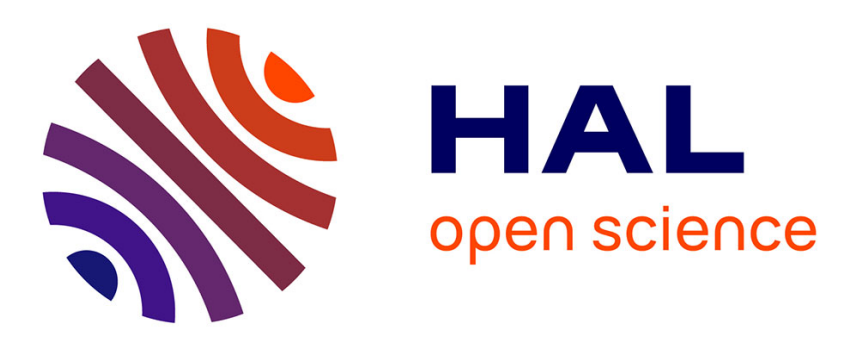

\title{
Cost of motor skill adaptation to new craft traits: Experiments with expert potters facing unfamiliar vessel shapes and wheels
}

Enora Gandon, Valentine Roux

\section{- To cite this version:}

Enora Gandon, Valentine Roux. Cost of motor skill adaptation to new craft traits: Experiments with expert potters facing unfamiliar vessel shapes and wheels. Journal of Anthropological Archaeology, 2019, 53, pp.229-239. 10.1016/j.jaa.2019.01.004 . hal-02958050

\section{HAL Id: hal-02958050 \\ https://hal.parisnanterre.fr/hal-02958050}

Submitted on 5 Oct 2020

HAL is a multi-disciplinary open access archive for the deposit and dissemination of scientific research documents, whether they are published or not. The documents may come from teaching and research institutions in France or abroad, or from public or private research centers.
L'archive ouverte pluridisciplinaire HAL, est destinée au dépôt et à la diffusion de documents scientifiques de niveau recherche, publiés ou non, émanant des établissements d'enseignement et de recherche français ou étrangers, des laboratoires publics ou privés. 


\section{Cost of motor skill adaptation to new craft traits: Experiments with expert potters facing unfamiliar vessel shapes and wheels \\ Enora Gandon $^{\mathrm{a}, *}$, Valentine Roux ${ }^{\mathrm{b}}$ \\ ${ }^{a}$ Institute of Archaeology, University College London, London, United Kingdom \\ ${ }^{\mathrm{b}}$ CNRS, UMR 7055, Nanterre, France}

\section{Introduction}

In archaeology, ceramic styles (shapes and decorations of vessels) are used as chronological markers due to the simple fact that they keep changing, sometimes very rapidly (Orton et al., 1993). The study of stylistic change has a long history (Hegmon, 1992). Stylistic diffusion is one of its aspects. Diffusion is considered a general mechanism to explain how style was transmitted within and between populations and, as a result, how similar shapes and/or decorations are found across time and space. This general mechanism has recently been revisited by evolutionary archaeology, a theoretical framework which is interested in individual actions and in particular in the mechanisms of cultural transmission between individuals (Eerkens and Lipo, 2007). One open question is the adaptation cost involved in the transmission of new styles, and whether this cost affects rates of change.

As discovered in ethnographic fieldwork, stylistic traits tend to be less resistant to change than technical aspects of traditional pottery making, and therefore diffuse more rapidly over large areas (David and Kramer, 2001; Gelbert, 2003; Gosselain, 2000; Hegmon, 1998; Roux, 2015; Stark et al., 2000). This difference has been explained in terms of learning mechanisms. Adopting new vessel shapes and/or new vessel decorations can be done through a simple exposure to the finished product, without direct interactions between the pot makers (Gelbert, 2003; Gosselain, 2000; Roux, 2015). Exposure to the vessels can occur in either publicly or privately, through those who either sell the pots, or buy and/or use them, that is, through merchants and/or consumers. Following this exposure, the new vessel shapes and/or the new decorations can be copied through individual learning, a process wherein an individual learns by him- or herself, modifying existing behavior through trial and error (O'Brien and Bentley, 2011). In contrast, learning new fashioning techniques requires the development of new motor skills and therefore social learning with a long-lasting contact between the transmitter (tutor) and the adopter (novice) (Kuhn, 2004; O'Brien and Bentley, 2011; Shennan, 2013; Shennan and Steele, 1999). This could be one factor explaining why techniques tend to be more resistant to change than styles.

Field experiment studies have been conducted to assess empirically the difficulties in learning new fashioning techniques, and to understand the mechanisms underlying the diffusion (or non-diffusion) of those techniques (Gelbert, 1997, 2003; Roux et al., 2018; Roux and Corbetta, 1989). Depending on the technique (wheel-throwing, coiling, molding, modeling by drawing), it has been shown that their motor skill learning takes between 2-3 years and 10 years and involves social learning. Such technical learning represents a high cost for individuals, this cost being a factor contributing to the general stability of the fashioning techniques (examples in Mayor (2010)). In contrast, it has typically been taken for granted that adopting new ceramic styles (shapes and/or decorations) does not present any challenges for motor skills, and consequently corresponds to a low cost for individuals whether these changes are small (as shown in seriation analyses) or dramatic (as shown by radical changes of shapes over time, as in Tell Arqa, Lebanon, 3rd millennium BC; Thalmann, 2006). This would explain how a single exposure to the new shape may be sufficient for transmission to occur although, at another level, the decorative style can be subject to selection, for example in the persistence of traits that signal identity (Dietler and Herbich, 1998).

At present, the lack of empirical data to assess the cost of adapting motor skills to new ceramic styles makes it difficult to understand the cultural processes involved in selecting and diffusing these styles. We assume that this cost (i) varies positively with the level of difficulty of the new style, and (ii) depends on the postures and gestures familiar to the craftsmen and on the ease with which they can be transferred to the new style (if the transfer is doable the cost will be low, and vice versa). Different acquisition costs may be associated with different modes of transmission (individual learning vs. social learning, respectively for a low vs. high cost). We may suspect that these different costs imply diverse socio-economic contexts for adopting the new trait.

Grounded in the evolutionary archaeological perspective, this study aims to assess the costs for the potter of adapting to new ceramic styles, and ultimately to understand better how these traits are selected and diffused. For that purpose, we analyzed the motor skills of traditional potters when confronted with new shapes. How do they adapt to the new production constraints? Do they have to develop new motor habits, or do they transfer the skills developed in their usual conditions of

\footnotetext{
* Corresponding author at: Institute of Archaeology, University College London, 31-34 Gordon Square, London WC1H 0PY, United Kingdom.

E-mail address: e.gandon@ucl.ac.uk (E. Gandon).
} 


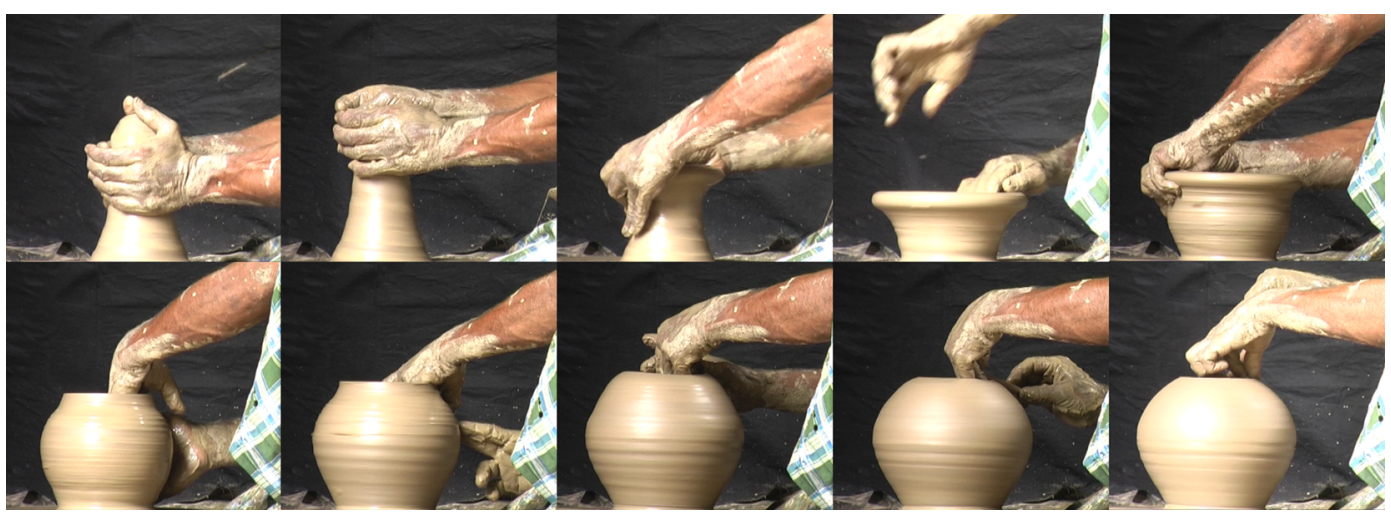

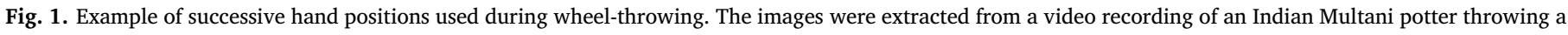
$2.25 \mathrm{~kg}$ sphere.

practice? We restricted the study to only pottery shapes which represent a part of pottery style. Decorations, which are another part of pottery style, are not considered here.

As a widespread and traditional skill, wheel-throwing provides an excellent artisan case for analyzing the adaptation of motor skills to new production constraints. Starting with a formless lump of clay the goal of wheel-throwing is to produce a pot - of a shape and size chosen in advance - using a wheel rotating in the horizontal plane at speeds varying between 50 and 150 rotations/min (e.g., Gandon et al., 2011a; Rye, 1981). In shaping the vessel potters successively deploy several distinctive hand positions exerting manual pressures onto the clay (Fig. 1). A given hand position can be used at different moments during the shaping process (Roux, 1989). Potters' hand positions are learnt from the tutor during apprenticeship and they constitute the observable aspects of the wheel-throwing skill.

Across cultures and time wheel-throwing skill has been practiced with different kinds of wheels that vary generally in the ways they are activated. So far, the evolutionary history and the diffusion of these various wheels have not been elucidated. Yet, as potter's tools, wheels constitute an integral part of ceramic traditions. Change in potter's tools and the related motor adaptation cost have not been studied, although the subject concerns major questions such as the spread of different types of wheel characterized by different mechanical properties. As an example, there are archaeological situations where different types of rotary instruments were adopted following contacts with distant social groups (adoption of the Palestinian and Mesopotamian turntables by northern Levantine potters; Roux and Thalmann, 2016). The lack of research in terms of motor skills adaptation to new rotary instruments prevents any complete analysis of their adoption. One secondary goal of the current investigation was to contribute to filling this gap. Theoretically, adopting a novel wheel does not imply the development of a new fashioning technique because all kinds of wheels allow potters to use their hands freely. Accordingly, we expect potters' hand positions to be unaffected when potters use an unfamiliar wheel. If this assumption is correct, the adoption of a new wheel would not represent a high cost for individuals, at least in terms of the hand skill essential for this technique.

In the present study, three field experiments were conducted in Jahangirabad (Uttar Pradesh, northern India), with expert potters from two potting communities: the Prajapati and the Multani Kumhar (Gandon et al., 2014a). In this region the wheels traditionally used are community-specific (Roux, 2013; Roux et al., 2017). The Prajapati potters use a hand-operated, high-inertia stick-wheel (also called flywheel) (Fig. 2, top panel), while the Multani Kumhar potters use a footoperated, low-inertia kick-wheel (also called foot-wheel) (Fig. 2, bottom panel). We asked seven participants to produce pots of familiar
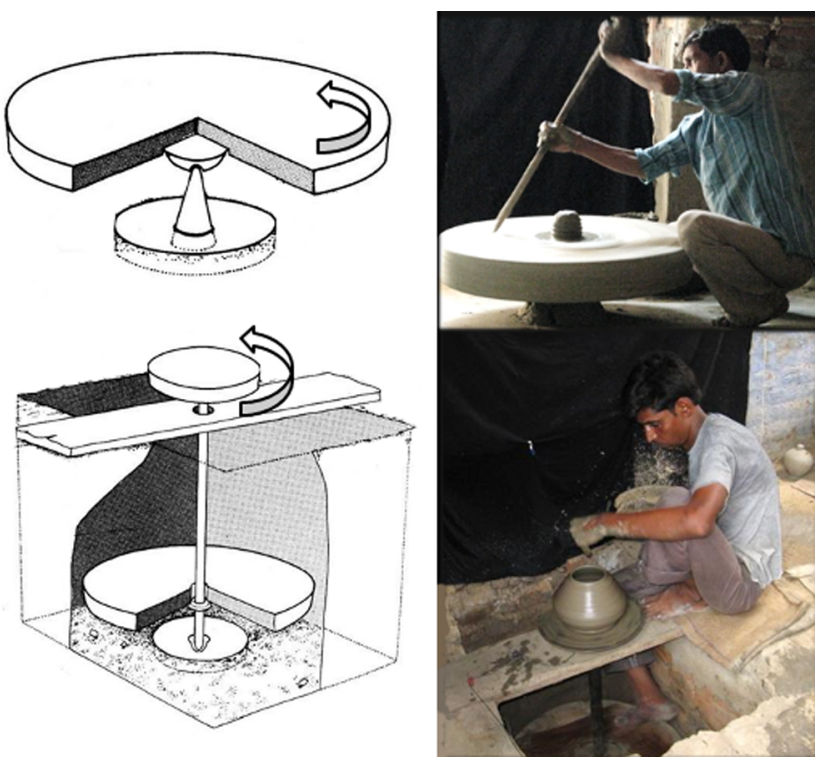

Fig. 2. The two common wheels used in northern India. Top panel: the high inertia stick-wheel used by the Prajapati potters. Bottom panel: the low-inertia kick-wheel used by the Multani potters. Drawings are adapted from Orton et al. (1993). The two wheels evoke distinct body positions: for the stick-wheel potters typically squat (sometimes they use a low stool), while for the kickwheel potters sit, one leg folded, on a wooden plank.

vs. unfamiliar shapes, using familiar vs. unfamiliar wheels. The gestural patterns defined as the successive hand positions used by the potters in the throwing process were video recorded to be then analyzed with a method inspired by ethology (Gandon, 2014; Gandon et al., 2013). This method - detailed below - provides an accurate quantification of variations in motor skills in different conditions of practice. In so doing we assessed the adaptation cost through the variations in the hand position repertoire from the familiar conditions of practice to the new ones.

\section{Materials and methods}

\subsection{Experimental setting}

Seven Indian expert potters participated in the study: three Prajapati potters (group Pr) and four Multani Kumhar potters (group MK). The three Prajapati potters are referred to as Pr1, Pr2, and Pr3 (Pr1 and Pr2 are father and son; Pr1 and Pr3 are uncle and nephew). The four Multani potters are referred to as MK1, MK2, MK3, and MK4 


\begin{tabular}{|c|c|c|c|c|}
\hline Money-Bank & Handiya & Kullar & Handi & Kulfi \\
\hline & & & & \\
\hline
\end{tabular}

Fig. 3. The five familiar shapes produced with self-chosen quantities of clay. From left to right: Money-Bank, Handiya, Kullar, Handi, and Kulfi. The four Prajapati potters reproduced the MoneyBank, Handiya, and Kullar; the three Multani potters reproduced the Money-Bank, Handi, and Kulfi.

(there is no close family relationship between the four MK potters). These two groups of potters belong respectively to Hindu and Muslim communities living in the same villages. The participants (all righthanded men) were all over 25 years of age and had a minimum of ten years of wheel-throwing experience (Mean \pm SD, Pr: $23.7 \pm 17.6 \mathrm{yrs}$ and MK: $18.3 \pm 7.3 \mathrm{yrs}$ ). They produce at least five different kinds of everyday objects for the local market, often in different sizes. In northern India the craft of pottery is a traditional activity: the skill is learnt through vertical transmission within endogamous castes that mass-produce standardized traditional objects (Kramer, 1997; Roux and Corbetta, 1989; Saraswati and Behura, 1966). Over the last few decades the trading networks of the two communities have become undifferentiated and, as a consequence, both communities tend to produce the same kinds of objects (Roux, 2013). Although the repertoires of the shapes produced are broadly shared by the two groups, as noted in the introduction, the wheels used are community-specific (Roux, 2013; Roux et al., 2017) (Fig. 2). The same soft gray clay is used by both communities.

A standardized experiment was set up in two pottery workshops one Prajapati and one Multani - in the same village of Jahanjirabad. Potters were initially asked to produce two different assemblages. The first assemblage (denoted Experiment 1) included five familiar shapes, referred to as Money-Bank, Handiya, Kullar, Handi, and Kulfi (see Fig. 3). These familiar shapes were produced in the usual conditions of practice, using self-chosen quantities of clay. The three Prajapati potters (Pr1, Pr2 and Pr3) produced the Money-Bank, Handiya, and Kullar, while the three Multani potters (MK1, MK2, and MK4) produced the Money-Bank, Handi, and Kulfi. Each potter produced five specimens of the same shape. In this first experiment, potters relied on their practical experience of the shape to be produced; no visual model was provided.

The second experiment (denoted Experiment 2) involved four unfamiliar shapes, referred to as cylinder (C1), bowl (C2), sphere (C3), and vase (C4), respectively. These unfamiliar shapes were produced using two predetermined quantities of clay, $0.75 \mathrm{~kg}$ (A) and $2.25 \mathrm{~kg}$ (B), for a total of eight conditions (C1A, C1B, C2A, C2B, C3A, 3B, C4A, and C4B; see Table 1). Models of the four unfamiliar shapes were presented in 2D-drawings that were displayed on the wall in front of the potter for the full duration of the experiment. These 2D-drawings of the models presented the four shapes but did not provide any indication of scale or the absolute dimensions to be produced: participants were simply instructed to reproduce the model shape faithfully and to throw vessels with the thinnest walls possible using the amount of clay provided $(0.75$ or $2.25 \mathrm{~kg}$ ). All the potters (three Pr and four MK) produced five specimens of each of the four shapes with each mass of clay. The participants had no prior experience in the production of the unfamiliar shapes. They only briefly practiced the task the day before the experiment, producing one or two vessels for each condition.

A week after the first two experiments, potters were again asked to produce the unfamiliar shape assemblage, this time using an unfamiliar wheel (denoted Experiment 3): three Prajapati potters (Pr1, Pr2 and Pr3) agreed to use the kick-wheel in the MK-workshop and three Multani potters (MK1, MK3, and MK4) agreed to use the stick-wheel in the Pr-workshop. In this third experiment, potters produced four specimens for each of the eight conditions (Table 1). Models were displayed as in Experiment 2. All potters tried the unfamiliar wheel the day before the experiment, throwing at least three pots of their choice. Unfortunately, because of time constraints imposed on the fieldwork, we were unable to set up an additional experiment with potters producing familiar shapes with unusual wheels.

\subsection{Data recording and analysis}

The experimental sessions were videotaped (Panasonic NV-GS320) and analyzed using Actogram timing software. We captured the gestural patterns (i.e. sequence of hand positions) used for throwing each pot, with measurements of the durations (seconds) spent in each position (Gandon, 2014; Gandon et al., 2013). A code (a number) was attributed to each specific hand position detected in each of the two groups and in each of the experimental conditions. In order to describe as objectively as possible the positions observed we established a repertoire ethogram in which each position was accurately defined and exemplified by several pictures. A total of 49 different hand positions were defined (see Fig. 1 for a small subset). The non-shaping actions (e.g. to wet the clay) were also timed but excluded from the total shaping time. For each vessel thrown we calculated the percentage of total shaping time (\%Shap) for which each of the 49 hand positions was used. Then, for each pot shaping, we obtained a repertoire of \%Shap defined as a vector of 49 values corresponding to the percentage of time spent by the potter using each of the 49 hand positions for shaping the pot. Given the fact that each potter used only part of the total hand position repertoire, several values in the vectors were equal to zero. Having established their normality, we ran an ANOVA on the number of

Table 1

The four unfamiliar shapes produced with $0.75 \mathrm{~kg}$ (A) and $2.25 \mathrm{~kg}$ (B) masses of clay by Prajapati and Multani potters. C1: cylinder, C2: bowl, C3: sphere, C4: vase.

\begin{tabular}{|c|c|c|c|c|c|c|c|c|}
\hline Shape & Cylinder & & Bowl & & Sphere & & Vase & \\
\hline \multicolumn{9}{|c|}{ Model (2D drawing) } \\
\hline Mass of clay $(\mathrm{kg})$ & 0.75 & 2.25 & 0.75 & 2.25 & 0.75 & 2.25 & 0.75 & 2.25 \\
\hline Condition & $\mathrm{C} 1 \mathrm{~A}$ & C1B & $\mathrm{C} 2 \mathrm{~A}$ & $\mathrm{C} 2 \mathrm{~B}$ & C3A & С3B & C4A & $\mathrm{C} 4 \mathrm{~B}$ \\
\hline
\end{tabular}


Table 2

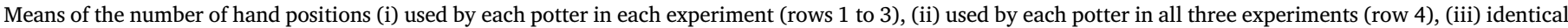

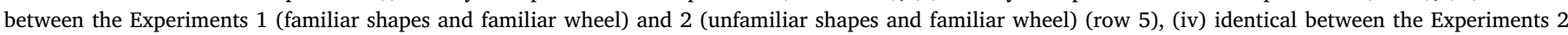

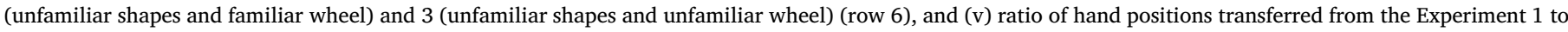
the Experiment 2 (row 7). Standard deviations are indicated in the last column for the three experiments and the mean individual repertoire.

\begin{tabular}{|c|c|c|c|c|c|c|c|c|c|c|}
\hline & & Pr1 & Pr2 & Pr3 & MK1 & MK2 & MK3 & MK4 & $\mathrm{m}$ & $s d$ \\
\hline 1 & Experiment 1 & 25 & 26 & 14 & 19 & 22 & & 22 & 21.3 & 4.4 \\
\hline 2 & Experiment 2 & 27 & 25 & 27 & 24 & 19 & 25 & 22 & 24.1 & 2.9 \\
\hline 3 & Experiment 3 & 27 & 25 & 28 & 25 & & 22 & 23 & 25.0 & 2.3 \\
\hline 4 & Mean individual repertoire & 33 & 31 & 31 & 34 & 28 & 25 & 30 & 30.3 & 3.0 \\
\hline 5 & Identical repertoire Exp. 1-2 & 20 & 21 & 13 & 12 & 13 & & 16 & 15.8 & \\
\hline 6 & Identical repertoire Exp. 2-3 & 25 & 23 & 25 & 22 & & 22 & 21 & 23.0 & \\
\hline 7 & Ratio of transfer Exp. 1-2 & 0.74 & 0.84 & 0.48 & 0.50 & 0.68 & & 0.73 & & \\
\hline
\end{tabular}

hand positions (used in Experiments 2 and 3) to evaluate the effects of shape (cylinder, bowl, sphere, and vase), mass ( 0.75 and $2.25 \mathrm{~kg}$ ), and type of wheel (familiar vs. unfamiliar).

\section{Results}

\subsection{Repertoire of hand positions for all shapes in the three experiments}

In total, 49 hand positions were identified in the study. Among this full repertoire 39 hand positions were used by the Pr potters and 43 by the MK potters. The two groups revealed large overlapping repertoires (33 positions were shared). Eight hand positions were individual (i.e. used by only one potter) and eight positions were used in only one group (by at least two potters). The repertoires of hand positions varied significantly between individuals: only ten hand positions were used by the seven potters. Table 2 details the mean numbers of hand positions used by each potter in the different experimental conditions. Throughout the three experiments individual potters used on average 30.3 ( \pm 3 ) different hand positions (Table 2). In comparison, the average numbers of hand positions used in the three experiments separately are smaller and not significantly different from one another: 21.3 ( \pm 4.4 ), 24.1 ( \pm 2.9 ), and 25.0 ( \pm 2.3 ), respectively for Experiments 1, 2, and 3. In Experiment 1, Pr3 used clearly fewer hand positions (14) than the other two Pr potters (25 and 26 respectively). This indicates that, although the shapes produced are the same, the varieties of hand positions and the sequences of hand positions depend on the individuals. Table 2 also presents the number of hand positions identical across several experiments. For the six participants having participated in the first two experiments (familiar vs. unfamiliar shapes), the number of identical hand positions between the two experiments is systematically smaller than the number of positions used in each of the two experiments taken separately. This shows that the potters changed part of their hand position repertoire when they produced the unfamiliar shapes; they abandoned certain positions (used for the familiar shapes) and adopted others. Yet, it is worthy of note that at least half the hand positions used for the unfamiliar shapes were transferred from the repertoire used for the familiar shape. For Pr1, Pr2, MK2 and MK4 this ratio of transferred positions represents two thirds, for Pr3 and MK1 it represents one half (Table 2). On the other hand, for the six participants having participated in Experiments 2 and 3 (familiar vs. unfamiliar wheels), the number of identical hand positions between the two experiments is almost the same as the number of positions used separately in each of the two experiments. This indicates that most of the hand positions used with the familiar wheel are transferred to the unfamiliar wheel.

\subsection{Repertoire of hand positions for each shape in the three experiments}

Fig. 4 presents the mean numbers of hand positions used for each shape separately in the three experiments, all potters combined. We observe an average number close to 13 hand positions with a minimum of 8 and a maximum of 17 hand positions. A first striking result is that changing of wheel has no effect; whether potters used the familiar or the unfamiliar wheel the size of the hand position repertoires was unchanged $(F(1,5)=-0.00, n s)$. On the other hand, Fig. 4 reveals that the clay mass manipulated had a significant effect; potters use a larger number of hand positions when throwing vessels with larger clay masses $(F(1,5)=8.81, p<.05)$. On average, potters used two more hand positions when throwing the larger vessels. With respect to the shape to be thrown, results show that the familiarity with the shapes did not influence the size repertoire. On average, potters used 12.7 and 13.7 hand positions when shaping respectively the familiar and un-familiar shapes (Fig. 4). In addition, between the four unfamiliar shapes tested (cylinder, bowl, sphere, and vase) no significant difference was

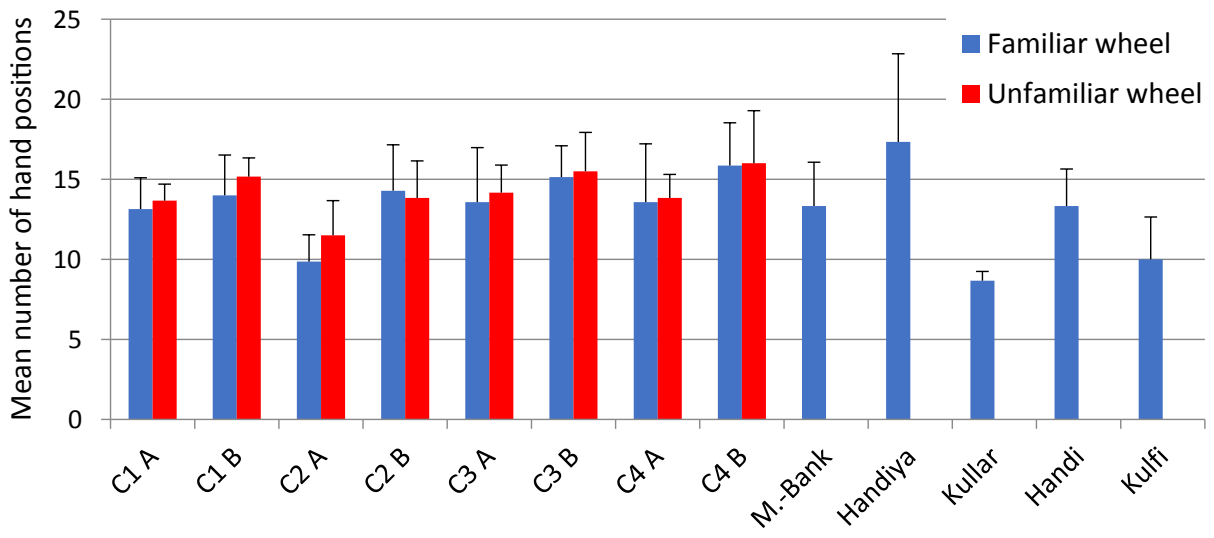

Fig. 4. Means and standard deviations (indicated by error bars) of the number of hand positions used by the potters when using a familiar and an unfamiliar wheel (blue and red respectively) to produce different shapes. C1: cylinder, C2: bowl, C3: sphere, C4: vase. A and $\mathrm{B}$ indicate 0.75 and $2.25 \mathrm{~kg}$ clay masses. C1A, C1B, C2A, C2B, C3A, C3B, C4A, and C4B are unfamiliar shapes; MoneyBank, Handiya, Kullar, Handi, and Kulfi are familiar shapes. (For interpretation of the references to colour in this figure legend, the reader is referred to the web version of this article.) 
observed in the size of the hand position repertoires $(F(3,15)=3.26$, $n s)$. However, the ANOVA revealed that throwing the $0.75 \mathrm{~kg}$ bowls (C2A) was accomplished with a smaller number of hand positions than throwing the other shapes $(F(3,15)=3.42, p<.05)$. When throwing the $0.75 \mathrm{~kg}$ bowls potters used 10.6 hand positions on average while they used 14.4 hand positions on average for the seven other conditions (C1A, C1B, C2B, C3A, C3B, C4A, and C4B). Interestingly, the two familiar open shapes Kullar and Kulfi were shaped with a mean number of hand positions close to that of the $0.75 \mathrm{~kg}$ bowls (8.7 and 10.0, respectively for the Kullar and Kulfi).

\subsection{The potters' gestural pattern in the three experiments}

The potters gestural patterns for producing vessels is presented in Fig. 5. This figure presents the cumulative percentage shaping time (\% Shap) of various hand positions used by the participants in the three experiments all potters, shapes, and masses included. Inspection of this figure brings out several noteworthy observations. At first, when $\operatorname{Pr}$ and MK potters produced the same set of shapes (in the Exp. 2 and 3), their respective gestural patterns were close to each other (Fig. 5, middle and top panels). On the other hand, when they produced a different set of shapes (in Exp. 1) their respective gestural patterns were different from each other (Fig. 5, bottom panel). This leads to the hypothesis that the shape parameter influences the gestural pattern. Indeed, the large distances between the Pr and MK lines were probably due to the different set of shapes produced by the two groups (Pr: Money-Bank, Handiya, Kullar; MK: Handi, Money-Bank, Kulfi) (Fig. 5, bottom panel). With respect to the familiarity of shapes, we note that the gestural patterns in Experiment 1 (familiar shapes) are close to those in Experiments 2 and 3 (unfamiliar shapes) (Fig. 5). Of the 37 different positions used in the Experiment 1, 29 positions are reused in the Experiment 2 and/or in the Experiment 3. Only eight positions (42 to 49) were exclusively used in the Experiment 1. This result confirms that the potters' motor habits are largely transferred from the familiar shapes to the unfamiliar ones. On the other hand, 12 hand positions $(16,17,18,19,20,25,28,29,31,37$, $39,41)$ were exclusively used in Experiments 2 and 3; among them five were individual $(17,29,31,39,41)$ (Fig. 5, middle and top panels). Finally, focusing on the middle and top graphs, we see similar gestural patterns in Experiments 2 and 3 indicating that potters transferred their motor habits from the wheel with which they are familiar to the wheel they are unfamiliar. Among the 41 different positions used in the Experiment 2, 38 positions are reused in the Experiment 3.
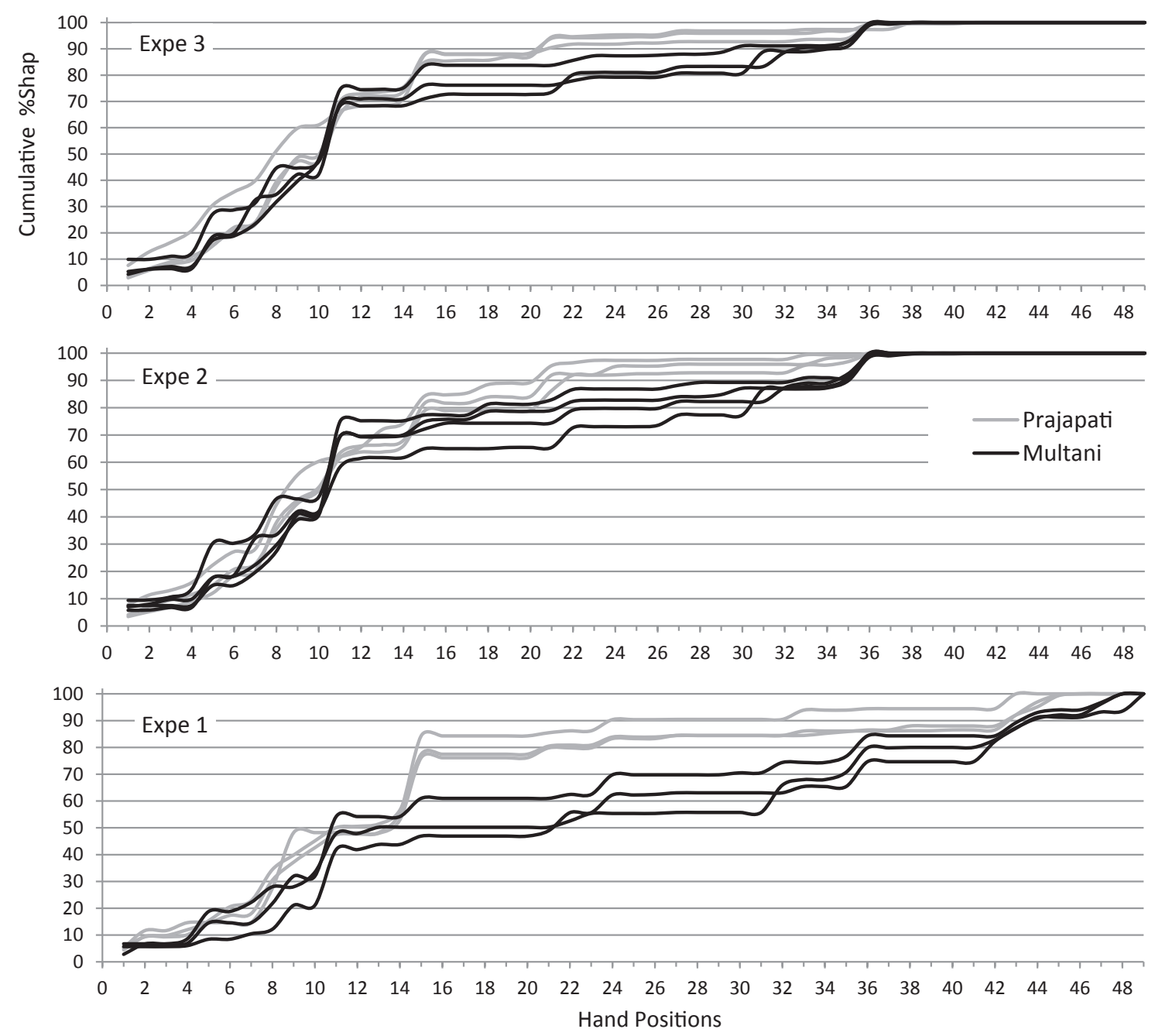

Fig. 5. Cumulative percentage shaping time (\%Shap) over the full hand position repertoire identified in the study through the three experiments for each potter, all shapes and masses included. Bottom graph: Experiment 1 (familiar shapes and familiar wheel), middle graph: Experiment 2 (unfamiliar shapes and familiar wheel), and top graph: Experiment 3 (unfamiliar shapes and unfamiliar wheel). Grey: Prajapati potters, and black: Multani potters. 


\subsection{The potters' gestural patterns in the first experiment}

Figs. 6 and 7 present the cumulative percentage shaping time (\% Shap) of various hand positions used by each participant in the first experiment (familiar shapes and wheels), for all five trials. First, we notice that the gestural patterns are reproducible for all the six potters. Indeed, in each graph the lines representing the five trials for a given potter producing a given shape are close to each other (Figs. 6 and 7). Secondly, we observe an influence of the individual on the gestural patterns. Indeed, on the six graphs, the lines of each potter are far apart from one another (Figs. 6 and 7). Looking at the Money-Bank for example (the shape produced by all six potters), we find that the gestural patterns used by the six potters are distant from each other. This individual influence is less pronounced in the Pr group, in particular for Pr1 and Pr2 when producing the Handiya and the Kullar (Figs. 6 and 7). Remembering that Pr1 and Pr2 are father and son the similarity of their gestural patterns is understandable. Inspection of the graphs also reveals a significant influence of the shape parameter on the gestural patterns. All potters used a different gestural pattern for the three shapes produced.
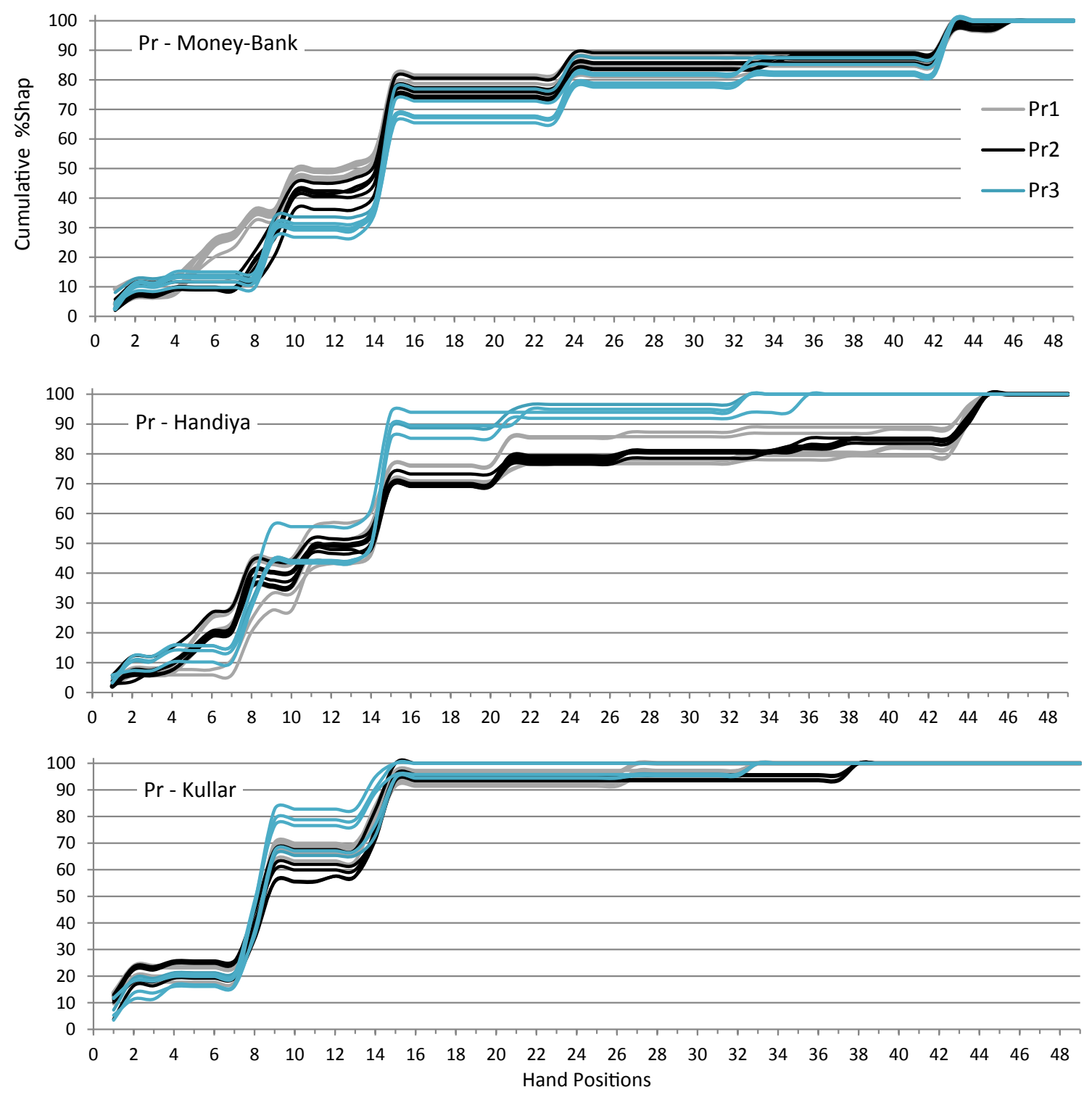

Fig. 6. Cumulative percentage shaping time (\%Shap) over the full hand position repertoire, for the three Prajapati potters participating in the Experiment 1 (familiar shapes and familiar wheels). Pr1 (grey), Pr2 (black), and Pr3 (blue) produced the Money-Bank, the Handiya, and the Kullar. For each shape, each of the five trials performed are presented. (For interpretation of the references to colour in this figure legend, the reader is referred to the web version of this article.) 

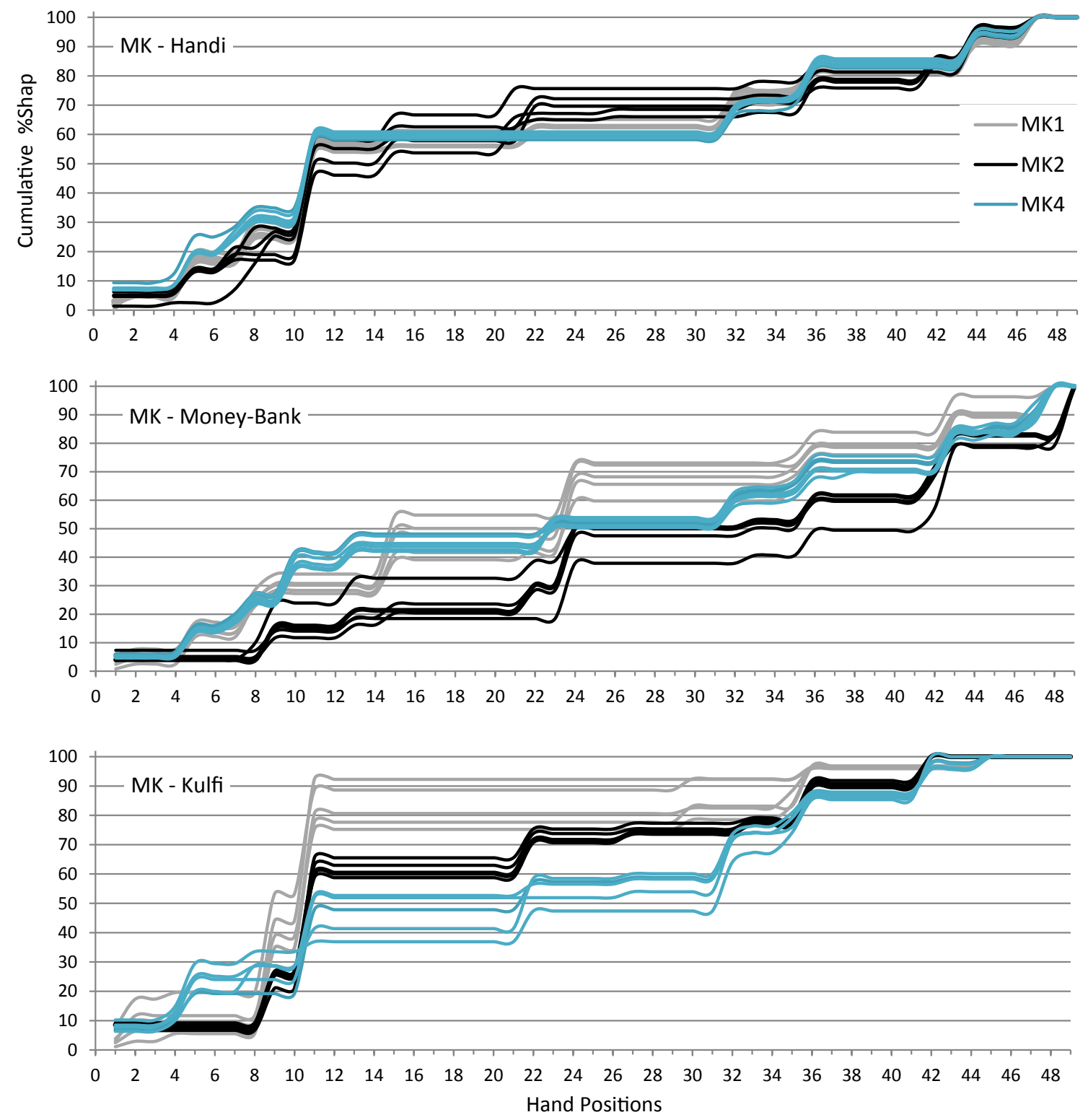

Fig. 7. Cumulative percentage shaping time (\%Shap) over the full hand position repertoire, for the three Multani potters participating in the Experiment 1 (familiar shapes and familiar wheels). MK1 (grey), MK2 (black), and MK4 (blue) produced the Handi, the Money-Bank, and the Kulfi. For each shape, each of the five trials performed are presented. (For interpretation of the references to colour in this figure legend, the reader is referred to the web version of this article.)

\subsection{Two representative potters' gestural patterns in the second experiment}

Fig. 8 shows the gestural patterns for two representative potters Pr2 and MK4 - in the second experiment (unfamiliar shapes produced with familiar wheels), for all five trials. For each of the four shapes with the two masses the lines representing the gestural patterns of the five trials are not significantly superimposed. This indicates that the reproducibility of the gestural patterns is poor, in particular compared with the reproducibility of the gestural patterns when potters produced familiar shapes (Figs. 6 and 7). Although Fig. 8 presents the gestural patterns of two participants only, the difference of reproducibility rates between Experiments 1 and 2 was observed for all potters who participated in these two experiments. This suggests that the gestural patterns of the familiar shapes are systematically more reproducible than those of the unfamiliar shapes. This also explains the degree of standardization of the resultant assemblages, the one for Experiment 1 being significantly higher than the one for Experiment 2 (Gandon et al., 2014a) (see on-line appendix for the raw data of the pots dimensions).
Next, we observe the influence of the parameters shape and mass in the Experiment 2. With respect to the shape, the gestural patterns for the cylinders are different from those for the bowls that are themselves different from those for the spheres and the vases, these latter being almost superimposed (Fig. 8, graphs A and B). In fact, the vase was a shape particularly difficult to fashion and potters produced almost a sphere instead (Gandon et al., 2011b, 2014b). This explains why the gestural patterns for the vases and spheres are close. Comparison between the graphs A and B, highlights the influence of the mass (Fig. 8). For each of the four shapes, the gestural patterns for the $0.75 \mathrm{~kg}$ pots are distinct from those for the $2.25 \mathrm{~kg}$ pots. The effects of the shape and mass were observable for all the participants, showing that they all adapted their gestural patterns to the characteristics (mass and shape) of the pots to be thrown. Scrutiny of the results reveals that this adaptation varied from one individual to another. More precisely, as observed in the Experiment 1, different individuals used different hand position repertoires for producing the same kind of pot. 

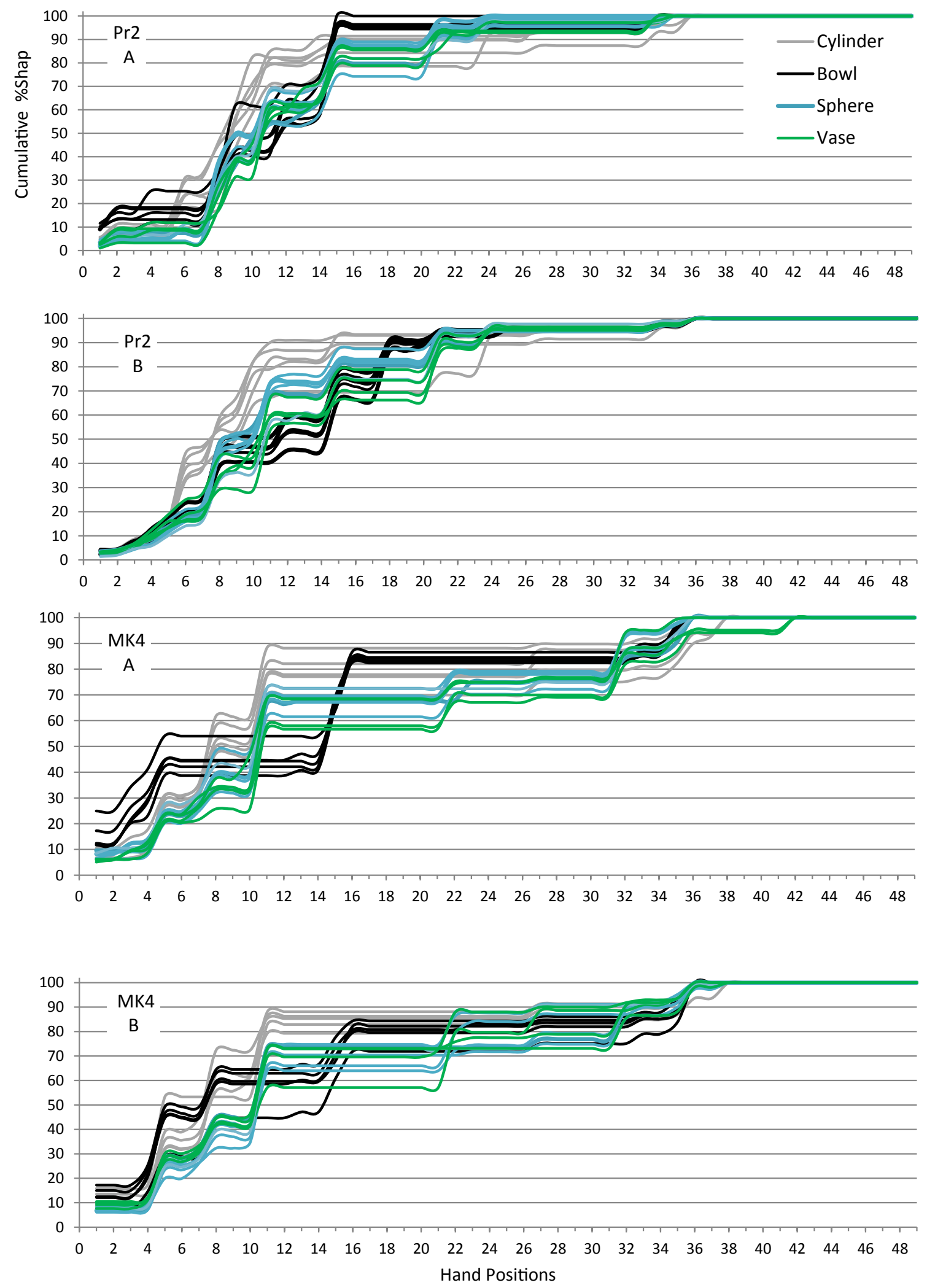

Fig. 8. Cumulative percentage shaping time (\%Shap) over the full repertoire, for two representative potters (Pr2 and MK4) in the Experiment 2 (unfamiliar shapes and familiar wheels). The four unfamiliar shapes reproduced were cylinder, bowl, sphere, and vase. A: $0.75 \mathrm{~kg}$ clay mass; and B: $2.25 \mathrm{~kg}$ clay mass. For each shape, each of the five trials performed are presented.

\section{Discussion}

Ceramic styles have been considered especially receptive to diffusion as opposed to fashioning techniques because they are said to be more visible (Gosselain, 2000). However, trait visibility does not explain why shapes and/or decorations could be diffused easily or why techniques or tools could not. This question was tackled here in terms of adaptation cost to new production constraints. Measuring this cost is a 
first step towards characterizing the favorable conditions for the adoption and diffusion of new craft traits. For this goal, we adopted an experimental approach working with seven expert potters from northern India. We analyzed their gestural patterns when producing (i) three familiar shapes with their familiar wheel (Exp. 1), (ii) four unfamiliar shapes (each shape in two clay masses) with their familiar wheel (Exp. 2), and (iii) four unfamiliar shapes (still in two clay masses) with an unfamiliar wheel (Exp. 3). To assess the reproducibility of behavior each shape was produced several times (five times in the Exp. 1 and Exp. 2; four times in the Exp. 3).

Several results emerge from these experiments. First, we underline the significant influence of the shape parameter on the hand positions used by the potters. Whatever the familiarity with the shape, potters used a specific set of hand positions for each shape. The larger number of hand positions is found with the bigger vessels of the same shape. But the hand position repertoire also varies from potter to potter. Thus, five of the seven potters used one or two uniquely individual hand position (s) reflecting individual traits of the potter's skills. These results suggest that potters have a toolbox of hand positions (30 on average, see Table 2) and select a subset of this toolbox (on average 13 hand positions for a given shape, see Table 2) depending mainly on the shape to produce even though there is an individual influence on this selection.

Accordingly, it is assumed that the more varied the shapes produced in a workshop, the larger the toolboxes of the potters working in that workshop. A potter mastering a large hand position repertoire easily finds those suitable for fashioning new shapes, as is shown by our results: when fashioning the unfamiliar shapes, the participants transferred a significant part of their usual hand positions repertoire (see Table 2 and Fig. 5). We assume that potters usually producing at least five different shapes in various masses (as was the case for the participants in our study) will be able to produce new shapes without a long training period. On the contrary, potters specialized in solely a few shapes will probably not adopt new shapes without a significant training period, particularly if they are specialized in small open shapes. Indeed, as shown by our results, the production of small open shapes (such as kulfi, kullar, and small bowl) requires a limited number of hand positions whose mastery is insufficient for fashioning pots of all shapes and sizes as shown by previous experiments (Roux and Corbetta, 1989).

The second main result of the study is the high reproducibility of the potters' behavior when producing the familiar shapes. This high reproducibility appears in the consistency of within-potter gestural patterns (see Figs. 6 and 7). By contrast, throwing the unfamiliar shapes gave rise to a lower reproducibility (see Fig. 8). As stated earlier, this explains the different degrees of standardization of the resulting assemblages - that for the familiar shapes being significantly higher than that for the unfamiliar shapes (Gandon et al., 2014a). Such a high reproducibility of motor skills (and of the resulting assemblages) is possible because traditional potters intensively produce the same set of ceramic shapes over several years. Yet, facing novel shapes, the reproducibility of behavior decreases, and consequently the assemblages' standardization. In fact, the very nature of potters' skill consists in the regulation of the pressures exerted on the clay. Even if the participants were able to transfer most of their familiar hand positions to the new shapes, we assume that they needed to tune their pressures for bringing about the precise novel shapes. This tuning does not imply the learning of new skills, but still, it probably requires a training period having to be measured by further experiments.

Overall, our results suggests that the cost of motor skill adaptation to novel shapes depends on the potters' expertise. This cost is low for highly expert potters able to make pots of various sizes and shapes - like the participants in our study. In this case, potters master the range of hand positions and the accurate motor skills required to explore through individual learning how to make novel shapes. The adaptation cost would be much higher for potters specialized in a few small items. For them, not only would the range of hand positions be limited, but their motor skills are probably not accurate enough to throw pots of different shapes and sizes. In other words, it is likely that for such lowskilled potters throwing new shapes requires the development of a higher level of motor skills. This learning will be costly in terms of time, two years or more depending on age (Roux and Corbetta, 1989). Previous studies on stone knapping revealed a similar link between craftsmen's level of expertise and their ability to adapt their gestures to unfamiliar tools (hammers of different masses) and raw material (glass) (Bril et al., 2005; Roux et al., 1995). We argue that the difference in adaptation cost between potters with large and small gesture repertoires means that, at the population level, the adoption and diffusion of new ceramic shapes may depend on the context of production, all else being equal. When the production is distributed between potters who master a wide range of vessel shapes, the context is favorable to the adoption of novel shapes because at the individual level the cost of adaptation is low. On the other hand, when the production is distributed between workers specialized in solely a few vessel shapes (in domestic production units for example), this context can limit the adoption of new shapes: it may be too costly for the workers to learn the required skills. But context with a differential distribution of tasks can also have the opposite effect with the adoption of new shapes despite their cost in terms of technical learning. Thus, in the north of the southern Levant, at the beginning of the Early Bronze I (around 3600 BCE), new groups settled down who mastered the manufacture of all utilitarian containers, with the exception of the storage jars, as shown by salient manufacturing errors (such as the general asymmetry of the jars) (Braun, 1997). Our results suggest that these new groups were not used to making this type of vessels that could have been originally made by specialized potters. A rupture with the distribution networks of these specialized vessels, caused by the movement of these groups, probably forced them to manufacture this type of jar despite their high cost in terms of skills.

The Prajapati and Multani potting communities traditionally use different wheels: the former uses a hand-driven high-inertia stick-wheel while the latter use a foot-driven low-inertia kick-wheel. Notwithstanding the geographical proximity of the two communities within the village of Jahanjirabad, borrowing the other community's wheel has not been observed (Roux et al., 2017). Nevertheless, for the purpose of the third experiment (unfamiliar shapes thrown on unfamiliar wheels) we were able to convince three Pr potters to come to the MK workshop and throw the unfamiliar shapes (that they had thrown on their own stick-wheel a week before) on the Multani kickwheel. Similarly, we were able to convince three MK potters to do the same on the kick-wheel at the Pr workshop. Results of Experiment 3 showed that, as expected, throwing with an unfamiliar wheel did not give rise to significant difficulties for the participants. This was predictable because, as mentioned in the introduction, both the stick-wheel and the kick-wheel allow potters to use their hands freely. Hence, even though the required postures and the mode of activation of the two wheels were profoundly different, once the wheel was revolving potters were able to transfer their hand positions to the new situation (see Table 2, Figs. 4, and 5). This functional independence between posture and manual activity can be explained by the mechanism of compensatory variabilities (Arutyunyan et al., 1969; Tuller et al., 1982). In goal directed actions performed by experts, body joints organize in coordinative structures to ensure the effectiveness of the end effector(s) (i.e. the body segment(s) directly performing the action). The movement variabilities produced at the different body joints compensate between them leading to the stability - and accuracy - of the end effector(s). When changing their usual posture, the coordinative structures of expert potters apparently reorganize to maintain a fine control of their hand positions. However, this postural change was uncomfortable for the MK potters. Interviewed after Experiment 3, two of them complained about the "painful squatting position" associated with the stick-wheel. Pr potters did not complain about the sitting position associated with the kick-wheel; yet, two of them said that it was 
difficult to si multaneously ac tivate the ki ck-wheel (with the right leg) and use their hands in fashioning the clay. Indeed, unlike rotating the high-inertia stick-wheel, rotation of the low-inertia kick-wheel needs to be maintained almost constantly, which requires an independent control of legs and arms. In short, adoption of a new wheel does not involve significant changes in fashioning skills, posture and mode of activation appear to be stronger constraints. It will be interesting for future research to examine thoroughly the learning that is needed for the potters to adapt to these constraints.

\section{Conclusion}

We have raised the question of the cost of motor skill adaptation to new vessel shapes and wheels to characterize the conditions favorable for the adoption and diffusion of n ew craft traits. For this purpose, we have studied the behavioral dimension of handicraft changes by analyzing how contemporary potters adapted their motor skills to novelty. Through three distinct field experiments we asked seven expert potters to produce familiar vs. unfamiliar shapes and to use a familiar vs. unfamiliar wheel. The observable aspects of the potters' motor skills (i.e. the succession of the hand positions) were systematically coded and quantitatively analyzed in each experiment.

Our results show that potters transferred a significant part of their hand position repertoires from the familiar shapes to the unfamiliar ones. Additionally, the hand position repertoires varied, for all participants, depending on the shape to be thrown (familiar or not). These results suggest that the ability of potters to fashion new shapes varies positively with the diversity of shapes they commonly produce. The more hand positions a potter masters, the more easily he can find the ones adapted to new shapes. In contrast, potters specialized in very few shapes (in particular small open shapes) would need a learning period in order to adopt new shapes. Wheel novelty did not affect the potters' hand positions. This is not surprising in the sense that both wheels tested (kick-wheel and stick-wheel) afford e qual c onditions f or using the hands. However, the sitting posture and the mode of activation of the wheels make that there is a cost of adaptation to the new instruments which could be higher than with shapes.

We conclude that new ceramic stylistic traits - defined in terms of shape - can be adopted by potters without significant m odification in their motor skill. This explains why these traits tend to be less resistant to change than technical aspects of pottery making. However, our results stress the fact that this adoption is certainly dependent on the craftsmen's level of expertise. Novel shapes will be easily adopted in a context where the ceramic production is in the hands of expert potters (i.e. potters who master the production of a wide range of shapes) because in this condition the cost of motor skill adaptation is low. As shown by our results, expert potters reproduced new shapes through individual learning. We assume that low-skilled potters (i.e. potters specialized in small vessels) would not achieve such adaptation to new shapes without a consistent social learning or external pressures. As for the wheels, results indicate that their adoption involve new postures. We encourage further studies to assess this postural cost of adaptation, which may be high (e.g. adoption of any technique using the squatting position by individuals used to sitting on a chair).

Finally, it is worth noting the individual aspect of the potters' motor skills highlighted in the present contribution. This should help us to improve our understanding of the individual signatures recently unveiled on mass-produced traditional ceramic shapes (Gandon et al., 2018; Roux and Karasik, 2018).

\section{Acknowledgements}

This project has received funding from the European Union's Horizon 2020 research and innovation programme under the Marie Sklodowska-Curie grant agreement No. 793451. We are grateful to the potters who participated in the experiments. We also wish to thank
James Steele and John Endler for their contribution to the revisions, and Reinoud Bootsma for supporting the experiments preparation.

\section{Appendix A. Supplementary material}

Supplementary data to this article can be found online at https:// doi.org/10.1016/j.jaa.2019.01.004.

\section{References}

Arutyunyan, G.A., Gurfinkel, V.S., Mirskii, M.L., 1969. Organization of movements on execution by man of an exact postural task. Biophysics 14 (6), 1162-1167.

Braun, E., 1997. Yiftah'el. Savage and Rescue Excavations at a Prehistoric Village in Lower Galilee, Israel. Israel Antiquities Authority, Jerusalem.

Bril, B., Roux, V., Dietrich, G., 2005. Stone knapping: Khambhat (India), a unique opportunity? In: Roux, V., Bril, B. (Eds.), Stone Knapping: The Necessary Conditions for A Uniquely Hominin Behaviour. Mc Donald Institute for Archaeological Research, Cambridge, pp. 53-72.

David, N., Kramer, C., 2001. Ethnoarchaeology in Action. Cambridge University Press, Cambridge.

Dietler, M., Herbich, I., 1998. Habitus, techniques, style: an integrated approach to the social understanding of material culture and boundaries. In: Stark, M. (Ed.), The Archaeology of Social Boundaries. Smithsonian Institution Press, Washington, D.C., pp. 232-263.

Eerkens, J.W., Lipo, C.P., 2007. Cultural transmission theory and the archaeological record: providing context to understanding variation and temporal changes in material culture. J. Archaeol. Res. 15 (3), 239-274. https://doi.org/10.1007/ s10814-007-9013-z.

Gandon, E., Pous, F., Coyle, T., Buloup, F., Bootsma, R.J., 2011a. Regulating rotation speed in wheel throwing: effects of mass and shape. In: Charles, E.P., Smart, L.J. (Eds.), Studies in Perception and Action IX. Psychology Press, New York, pp. 196-201.

Gandon, E., Casanova, R., Sainton, P., Coyle, T., Roux, V., Bril, B., Bootsma, R.J., 2011b. A proxy of potters' throwing skill: ceramic vessels considered in terms of mechanical stress. J. Archaeol. Sci. 38 (5), 1080-1089. https://doi.org/10.1016/j.jas.2010.12. 003.

Gandon, E., Bootsma, R.J., Endler, J.A., Grosman, L., 2013. How can ten fingers shape a pot? Evidence for equivalent function in culturally distinct motor skills. Plos One 8

(11), e81614. https://doi.org/10.1371/journal.pone.0081614.

Gandon, E., 2014. To what extent do traditional motor skills reveal a cultural model? Fields experiments with expert French and Indian potters. Annales de la Fondation Fyssen 29, 47-68.

Gandon, E., Coyle, T., Bootsma, R.J., 2014a. When handicraft experts face novelty: Effects of shape and wheel familiarity on individual and community standardization of ceramic vessels. J. Anthropol. Sci. 35, 289-296. https://doi.org/10.1016/j.jaa.2014. 06.008 .

Gandon, E., Roux, V., Coyle, T., 2014b. Copying errors of potters from three cultures: predictable directions for a so-called random phenomenon. J. Anthropol. Sci. 33,

99-107. https://doi.org/10.1080/10407413.2018.1438200.

Gandon, E., Coyle, T., Roux, V., Endler, J.A., Bootsma, R.J., 2018. Individuals amongst the pots: how do traditional ceramic shapes vary between potters? Ecol. Psychol. 1-15. https://doi.org/10.1080/10407413.2018.1438200.

Gelbert, A., 1997. De l'élaboration au tour au tournage sur motte: difficultés motrices et conceptuelles. Techniques et Cultures 30, 1-23.

Gelbert, A., 2003. Traditions céramiques et emprunts techniques dans la vallée du fleuve Sénégal. Editions de la Maison des sciences de l'homme, Editions Epistèmes, Paris.

Gosselain, O., 2000. Materializing identities: an African perspective. J. Archaeol. Method Theory 7 (3), 187-217. https://doi.org/10.1023/A:1026558503986.

Hegmon, M., 1992. Archaeological research on style. Ann. Rev. Anthropol. 21 (1), 517-536.

Hegmon, M., 1998. Technology, style, and social practice: archaeological approaches. In: Stark, M. (Ed.), The Archaeology of Social Boundaries. Smithsonian University Press, Washington D.C., pp. 264-279.

Kramer, C., 1997. Pottery in Rajasthan: Ethnoarchaeology in Two Indian Cities. Smithsonian Institution Press, London.

Kuhn, S., 2004. Evolutionary perspectives on technology and technological change. World Archaeol. 36 (4), 561-570. https://doi.org/10.1080/0043824042000303737. Mayor, A., 2010. Traditions céramiques dans la boucle du Niger. Ethnoarchéologie et histoire du peuplement au temps des empires précoloniaux. Africa Magna verlag, Frankfurt am Main, Germany.

O'Brien, M.J., Bentley, R.A., 2011. Stimulated variation and cascades: two processes in the evolution of complex technological systems. J. Archaeol. Method Theory 18 (4), 309-337. https://doi.org/10.1007/s10816-011-9110-7.

Orton, C., Tyers, P., Vince, A., 1993. Pottery in Archaeology. Cambridge University Press, Cambridge.

Roux, V., 1989. Development of a taxinomy to measure throwing difficulties of prehistorical and protohistorical ceramic vessels. In: Roux, V. (Ed.), The Potter's Wheel. Craft Specialization and Technical Competence. Oxford and IBH Publishing, New Delhi, pp. 93-145.

Roux, V., 2013. Spreading of innovative technical traits and cumulative technical evolution: continuity or discontinuity? J. Archaeol. Method Theory 20 (2), 312-330.

https://doi.org/10.1007/s10816-012-9153-4.

Roux, V., 2015. Standardization of ceramic assemblages: Transmission mechanisms and 
diffusion of morpho-functional traits across social boundaries. J. Anthropol. Archaeol. 40, 1-9. https://doi.org/10.1016/j.jaa.2015.04.004.

Roux, V., Bril, B., Dietrich, G., 1995. Skills and learning difficulties involved in stone knapping: the case of stone-bead knapping in Khambhat, India. World Archaeol. 27 (1), 63-87. https://doi.org/10.1080/00438243.1995.9980293.

Roux, V., Bril, B., Cauliez, J., Goujon, A.L., Lara, C., Saulieu de, G., Zangato, E., 2017 Persisting technological boundaries: social interactions, cognitive correlations and polarization. J. Anthropol. Archaeol. 48, 320-335. https://doi.org/10.1016/j.jaa.

Roux, V., Bril, B., Karasik, A., 2018. Weak ties and expertise: crossing technological boundaries. J. Archaeol. Method Theory 25 (4), 1024-1050.

Roux, V., Corbetta, D., 1989. Wheel-throwing technique and craft specialization. In: Roux, V. (Ed.), The Potter's Wheel. Craft Specialization and Technical Competence. Oxford and IBH Publishing, New Delhi, pp. 1-91.

Roux, V., Karasik, A., 2018. Standardized vessels and number of potters: looking for in dividual production. In: Vukovic, J., Miloglav, I. (Eds.), Artisans Rule: Product Standardization and Craft Specialization in Prehistoric Society. Cambridge Scholars

Roux, V., Thalmann, J.P., 2016. Évolution technologique et morpho-stylistique des assemblages céramiques de Tell Arqa (Liban, 3e millénaire av. J.-C.): stabilité sociologique et changements culturels. Paléorient 42 (1), 95-121.

Rye, O.S., 1981. Pottery Technology. Principles and Reconstruction. Taraxacum Press, Washington D.C.

Saraswati, B., Behura, N.K., 1966. Pottery Techniques in Peasant India. Anthropological Survey of India.

Shennan, S., 2013. Lineages of cultural transmission. In: Roy, E., Lycett, S.J., Johns, S.E (Eds.), Understanding Cultural Transmission in Anthropology: A Critical Synthesis. Berghahn Books, Oxford, pp. 346-360.

Shennan, S., Steele, J., 1999. Cultural learning in hominids: a behavioural ecological approach. In: In: Box, H., Gibson, K. (Eds.), Mammalian Social Learning. Symposia of the Zoological Society of London, vol. 70. CUP, Cambridge, pp. 367-388.

Stark, M.T., Bishop, R.L., Miska, E., 2000. Ceramic technology and social boundaries: cultural practices in Kalinga clay selection and use. J. Archaeol. Method Theory 7 (4), 295-332. https://doi.org/10.1023/A:1026518922642.

Thalmann, J.P., 2006. Tell Arqa, 1. Les niveaux de l'âge du Bronze. Institut français du Proche-Orient, Beyrouth.

Tuller, B., Fitch, L., Turvey, M.T., 1982. The Bernstein perspective: II. The concept of muscle linkage: or coordinative structure. In: Kelso, J.A.S. (Ed.), Human Motor Behavior: An Introduction. Lawrence Erlbaum Associates, Inc., Hillsdale, New Jersey, pp. 253-271. 